Portland State University

PDXScholar

\title{
The Library Has Infinite Streaming Content, but Are Users Infinitely Content? The Library Catalog vs. Vendor Platform Discovery
}

Jian Wang

Portland State University, jian@pdx.edu

Elsa Loftis

Portland State University, eloftis@pdx.edu

Follow this and additional works at: https://pdxscholar.library.pdx.edu/ulib_fac

Part of the Cataloging and Metadata Commons, and the Collection Development and Management Commons

Let us know how access to this document benefits you.

\section{Citation Details}

Wang, Jian and Loftis, Elsa, "The Library Has Infinite Streaming Content, but Are Users Infinitely Content? The Library Catalog vs. Vendor Platform Discovery" (2020). Library Faculty Publications and Presentations. 310.

https://pdxscholar.library.pdx.edu/ulib_fac/310

This Post-Print is brought to you for free and open access. It has been accepted for inclusion in Library Faculty Publications and Presentations by an authorized administrator of PDXScholar. Please contact us if we can make this document more accessible: pdxscholar@pdx.edu. 
The library has infinite streaming content, but are users infinitely content? The library catalog vs. vendor platform discovery

Jian Wang and Elsa Loftis

Library, Portland State University, Portland, Oregon, United States

Jian Wang, Professor, is the Electronic and Continuing Resources/Applied Linguistics

Librarian.

jian@pdx.edu,

Elsa Loftis, Assistant Professor, is the Humanities and Acquisitions Librarian at Portland State University.

eloftis@pdx.edu, ORCID ID: https://orcid.org/0000-0001-9858-4347 


\title{
The library has infinite streaming content, but are users infinitely content? The library catalog vs. vendor platform discovery
}

\begin{abstract}
Despite the widespread adoption of streaming video by academic libraries, there has been little discussion about how video content is discovered and accessed through the library catalog as compared to vendor platforms. This article explores the current status of video resources in the library catalog to better understand how users find and access streaming content. MARC records were evaluated, and searches were performed to gauge issues related to metadata quality and its impact on discovery. The study reveals new trends in how users access streaming content for teaching, learning, and research.
\end{abstract}

Keywords: streaming video; library catalog; academic libraries; discoverability; analytics

\section{Introduction}

Streaming video "is becoming a mainstay on college campuses” (Dixon, 2017) and is now well established as an academic library service. According to the Primary Research Group survey, only 33\% of U.S. academic libraries provided access to streaming video in 2010 , but this figure grew to $70 \%$ by 2013 , and increased to $84.5 \%$ in 2015 (survey reports by farrelly \& Hutchison, 2014, 2016). Today, video content is ubiquitous, and has become an essential part of the academic library's holdings. This trend will continue as the number of distance learning programs continues to expand, leading faculty and students to rely on video resources along with other content such as journals, books, and databases for their teaching, learning and research needs (Strauch and Gilson, 2016; Leonard, 2015; Lohmann and Frederiksen, 2018, Hoover, 2016). 
This study was undertaken at Portland State University (PSU), a public urban university in the state of Oregon with an enrolment of approximately 28,000 students, and categorized as an R2: Doctoral University and governed by a board of trustees.

At PSU, fully online course offerings have increased between 2014 to 2019 by $114 \%$, while enrolment in these courses over the same period has increased by $95 \%$. This has happened while unique course offerings of in-person classes decreased by $14 \%$ with a 21\% drop in student enrolment over those same five years (Data from PSU Datamaster Database, https://datamaster.pdx.edu/, 2019). This is consistent with national trends (Palvia, Aeron, Gupta, et al., 2018). The increased reliance upon online courses at PSU will require more robust online resource offerings from the Library to keep pace with these enrolment trends. This often means that instructors strongly favour streaming media to physical formats when video material is used as a part of or as a supplement to an online course.

\section{Literature review}

The streaming format has been embraced by students, faculty and libraries, as is well documented in the current literature. Faculty use library-provided streaming services not only as a pedagogical tool in the classroom but also as a way of informing discussion, enriching understanding, and reinforcing topics covered by course material (Otto, 2014; Strauch and Gilson, 2016; Lohmann and Frederiksen, 2018).

According to a 2015 SAGE report, $68 \%$ of students watch videos in the classroom and 79\% watch videos voluntarily (outside the classroom) to help further their understanding (Leonard). Similar studies also reveal how students use video as a way of improving practical skills, in self-guided work, or as part of a specific assignment, a "flipped classroom,” an introduction to a research topic, etc. (Dixon, 2017; Strauch and Gilson, 2016). 
Lohmann and Frederiksen (2018) confirm librarians’ strong support for the expansion of streaming video collections and services (provided that faculty are aware of these resources), citing faculty's strong preference for streaming video over DVD recordings in a recent survey study.

Despite the rapid growth and use of streaming video content in higher education, challenges still remain as noted in the literature for some time. Issues associated with acquisitions, licensing, and copyright are extensively discussed in the areas of “purchase versus lease”, “DDA versus mediated purchasing”, “packages versus individual titles”, “aggregator or publisher platform”, “perpetual access versus term licensing”, as well as copyright and fair use (farrelly \& Hutchison Surdi, Lohmann \& Frederiksen, 2014, 2016, 2018). Technical specifications including ease of integration into online courses and ease of use with multiple viewing devices are also addressed (Wong, 2014). Cases studies with workflow issues are reported by several authors (Leffler, Hayden \& Enoch, 2017; Shephard, 2003; Wahl, 2017).

Recent studies drawn on surveys of students, faculty and librarians reveal that lack of awareness and discovery issues are the top barriers keeping faculty and students from making greater use of video content (Dixon, 2017; Otto, 2014; farrelly and Hutchison, 2016; Lohmann and Frederiksen, 2018). As Lohmann and Frederiksen (2018) note in their survey, only $27.7 \%$ of their faculty use the library discovery tool to search for video, as compared to $83.3 \%$ who use a search engine such as Google. Otto (2014) found that many faculty don’t recognize the library catalog as the primary discovery tool and most find the catalog “difficult to search and/or navigate," stating that "the 'needle in a haystack' issue is likely a significant part of the discovery problem.” 
Earlier findings (Barford \& Westonh, 1997; Shephard, 2003) are noticeably similar to those presented in recent literature cited in this article, further demonstrating that lack of familiarity and findability are the two major issues impeding the use of streaming content. Moreover, Beisler, Bucy \& Medaille, (2019), noted that "Discovery is therefore a primary concern for libraries with streaming video collections” (p. 16) in a more recent study.

The literature review for this study shows possible barriers or challenges to using streaming media that fall outside of the scope of this paper. These issues include content availability, licensing models, usability of vendor platforms, bandwidth and other IT support, marketing of the resources, as well as cost containment. No study has yet been conducted to precisely investigate and document how users find and access streaming content through the library catalog as compared to vendor platforms.

In an effort to discover how local users look for streaming content and how the integration and metadata of video content in the library catalog impacts the findability of this type of visual resource, the authors developed the following research questions. RQ1. Where is streaming content discovery headed?

RQ2. How far have libraries come with video integration in the discovery system?

\section{Background Information}

Like many academic libraries, the PSU Library started offering some Alexander Street Press products in the early 2000's, including Classical Music Library, Jazz Music Library, Counselling and Therapy in Video, Education in Video, Silent Film Online, and Ethnographic Video Online. The advent of this new type of resource and format enriched the library collections and user experience, but also introduced the complication of transitory collections that require constant updates and management similar to other electronic resources. One of the challenges in providing access to 
streaming collections was the lack of available bibliographic data, in addition to other issues such as access, electronic management system and external bibliographic utilities, link resolver, proxy, vendor data, etc. However, this also created an opportunity; it pushed the library to think creatively and to retool workflows at the same time. To absorb this new work seamlessly while keeping up with the cataloging, a local solution was developed and implemented in 2013, i.e., re-purposing metadata for greater efficiency. Inspired and informed by best practices recommended by the Library of Congress (Library of Congress, 2008), the library took advantage of existing bibliographic records in DVD, sound recording, motion pictures or other formats and created original MARC records via batch processes based on a locally developed standard cataloging template and procedure to ensure unique identifiers and fields for video format were compliant. These records were then contributed to OCLC through batch uploads to share with other libraries in the cataloging community.

Coincidentally, during the same year, the PSU Library, part of the Orbis Cascade Alliance (a consortium of public and private academic libraries in Washington, Oregon, and Idaho), joined forces with 36 other member institutions and began to prepare for a two-year-long process of migration to a shared Ex Libris’s cloud-based Alma library management system (LMS) and Primo discovery interface (Romaine and Wang, 2017). The Library completed its migration in the summer of 2014. One of the authors had opportunities to serve on several working groups within the Alliance Collaborative Technical Services Team before and after the migration, and was also involved with the initial conversation and investigation with Alliance colleagues about shared record management for streaming videos in the consortia catalog (Alma Network Zone) after migration. Member institutions, especially small libraries, wanted to leverage the value of the consortia Network Zone to do central record management in 
order to keep pace with the volume of streaming content purchased through consortia subscriptions and to mitigate duplicated energy for each library to load the same records separately into Alma. Librarians in the Alliance have been striving to "increase the efficiency of bibliographic production for all libraries through increased cooperation and increased sharing of bibliographic records, and by maximizing the use of data produced throughout the entire 'supply chain' for information resources” as recommended by the Library of Congress (Library of Congress, 2008). ExLibris’ Alma system has helped move toward this goal, especially in the management of electronic resources.

It has been five years since PSU's migration to Alma/Primo. With the acquisition of new subscription streaming media packages, including Academic Video Online, Kanopy, Films on Demand, Docuseek2, Medici.tv, the volume of streaming content has expanded dramatically. Currently, the library is offering more than 89,300 video titles (based on Alma Analytics as of June, 2019) accessible to students and faculty through the library's catalog (Ex Libris Primo Discovery layer).

Despite the proliferation of streaming video content available through the library catalog, some PSU librarians suspect that students do not look for videos in the library catalog as a starting point for their academic needs. They also note that some students go to library subscription streaming platforms directly, but often get understandably frustrated when navigating multiple databases to search for what they need. In response to this concern and for the purpose of gaining a better understanding of how users find and access streaming videos at academic libraries, the authors attempted to determine the current status of streaming video content in library catalogs and where discovery is taking place. 


\section{PSU librarians' experiences and perceptions}

This study began by gathering informal feedback from PSU librarians on their experiences and perceptions of faculty and students in finding and accessing videos. This was conducted through conversations and an informal Google survey form (see Appendix).

It is interesting to note that PSU librarians believe only a small number of students (27.3\%) use the library catalog (Primo discovery interface) to find and access streaming content. This perception is similar to that of a 2018 faculty survey conducted by Lohmann and Frederiksen, suggesting that this general concern still exists. Also, librarians perceive that only $18 \%$ of faculty and students use vendor platforms in the survey. This observation differs from the authors' original notion that students tend to go directly to vendor platforms, such as Kanopy, to search for streaming content. Most library faculty say that many students (36.4\%) find and access videos via links in the D2L course management system, which is expected due to an increased number of online courses being offered at PSU. Other comments theorize that students don't know where to go or how to find videos when their professor said the library had these videos online. This is also true of faculty. One librarian remarked that faculty often find a film they like and request it as a streaming film, whether or not it really is available in that format. Often, faculty send the Amazon link for the DVD and ask liaison librarians to find a streaming version. These conclusions are fairly anecdotal and further research is needed to address how students and faculty themselves perceive discovery of streaming media.

Regarding the greatest challenges in the library’s offering streaming content, PSU librarians identify discoverability and accessibility as major concerns besides costs as an uncertainty, which is also consistent with the results of other studies cited in the literature (Bossegna, et al, 2014, Beisler et al, 2019). Librarians are also aware of 
challenges relating to the wide variety of acquisitions models and pricing structures of streaming video content which has changed the landscape of PSU Library offerings. For example, the PSU library utilized a patron-driven model with the vendor Kanopy, but after three years of rising costs, it was decided to opt for a mediated version which was a significant cost saving. Other common examples of streaming acquisition is through subscription collection, where certain titles are added and removed periodically by the vendor. Differences such as these impact librarians’ collection development strategies and crucially, the workflows of technical services staff. Libraries must keep pace with changing collection types and acquisition models in order to maintain a solid representation in their catalog of actual entitlements.

When discussing the ease of using the library catalog to search for streaming content, varying opinions are reported. Some PSU librarians think that it’s pretty easy to use the library catalog for video discovery because they are an "expert," and also "most films seem to have been cataloged at the item level,” though many echo the need for continued enhancement of the library's Primo discovery tool.

\section{Discovery and access}

As literature and direct experience have shown, streaming content discovery seems to be headed everywhere at present because users are directed to multiple places, such as Internet search engines, the library website displaying a list of streaming film hosting platforms, the library’s Search Widget Box (for example, a pre-search filter for videos in a discovery system), and the library catalog. This helps shed some light on why faculty and students are perplexed when it comes to identifying and finding scattered and overwhelming streaming resources.

It is interesting to note from a recent study by Beisler, Bucy, \& Medaille (2019), that the library is not the primary means instructors use to discover streaming 
material, but that they often go to YouTube or other Internet sources. The primary benefits of using library resources that faculty state is that they know they have copyright compliance for class use, and high quality material. (p. 16).

This study underscores the need for a centralized search and discovery interface so that faculty and students do not need to visit multiple sites of varying quality to search for known items and browse for available material. "It is essential to establish tools to identify and access this content without requiring users to search multiple access points or interfaces," as stated by farrelly, one of the recognized experts in the field of media librarianship (Zabel, 2014). "Catalog searching, retrieval, and navigation must be improved to aid discovery of the video 'needle in the haystack' (Otto, 2014). Also, the Association of College and Research Libraries (ACRL) has established guidelines to support and guide academic libraries in clarifying their role and responsibility for the stewardship of media collections and services in academic libraries. Specific guidance on the Bibliographic Access and Cataloging includes the following (ACRL, 2018):

- Media resources should be made discoverable through the same retrieval mechanisms available for other library materials.

- Media resources should be cataloged in accordance with current national standards and practices, including full subject access, description, classification, and system and accessibility requirements.

- Media resources should be cataloged in a timely fashion, with sufficient support for catalogers, equipment, training and bandwidth to ensure that these resources are not backlogged.

- Summary statements in bibliographic records should supply users with important information about the content and purpose of media resources. 
Undoubtedly, "Library catalogs should represent the holdings of the library regardless of format, including bibliographic record, holdings, and URL maintenance” (ACRL, 2018). Streaming media resources are no exception, as use of video materials continue to grow and be added to library collections. The convenience of the 'one stop shopping' strategy for all library materials is even more desirable and likely to remain so moving forward as technology continues to evolve and library systems and services continue to improve.

Shapiro (2018) emphasizes the necessity of formulating a philosophy of discovery that is consistent with library values, and affirmed that "the ideal discovery layer would be a simple Google-like search box that obviates the need for multiple database/catalog search interfaces and provides the convenience of one stop shopping"(p. 671).

The need to have a “Google-like” and ‘one-stop shop’ discovery search engine for all library materials is being addressed by the next generation of discovery tools such as Ex Libris’ Primo (Asher, Duke, \& Wilson, 2013; Hanrath \& Kottman, 2015 ). It is hoped that these tools would allow libraries to aggregate metadata from a wide range of content providers, make it searchable in a centralized index of data reservoir, and provide a unified library user experience for all contents.

Discovery services, such as Primo, have helped libraries provide enhanced discovery and facilitate the retrieval of relevant materials, especially in the area of full text articlelevel discovery. However, there is still much to do regarding streaming content findability, as stated by Breeding (2015):

Discovery services have relatively weak support for the presentation and manipulation of images, video, digital recordings, and other rich media objects... the impact of discovery services would certainly be enhanced as they 
become less exclusively oriented toward text and gain greater capabilities for the growing body of content based on other types of media. (p. 34)

Surprisingly, a 2016 study reveals that nearly a quarter of academic libraries do not provide title-level catalog records for their streaming videos; and still many libraries do not catalog some of their streaming videos; $15 \%$ do not catalog any video content despite the availability of vendor supplied MARC records (farrelly and Hutchison Surdi). To explore how far libraries have come with video integration in the discovery system, the authors conducted an inquiry using an analytic approach in an attempt to assess current trends from both cataloging and discovery perspectives.

\section{Method}

Data analytics were collected from both the library catalog and discovery service (Ex Libris' Alma and Primo Analytics), and the vendor supplied usage reports to examine how and where users discover and access library paid streaming video content. Additionally, MARC records were evaluated, and various searches were performed on randomly selected titles to gauge potential issues related to metadata quality that could impact discovery through the library catalog and vendor platforms. Comparisons were made through data analysis.

\section{Detailed steps}

- Create sets of all MARC records for the identified streaming packages, including Academic Video Online (AVON), BBC Shakespeare Plays, British Pathe, C-Span Video Library, Docuseek2, Films on Demand, Kanopy, Medici.tv, Psychotherapy.net, and World Newsreels Online. One might note that 
the selected contents vary from very large collections to much smaller ones with subject specific focus. The intent is to get a more comprehensive picture of metadata records for streaming video content.

- Examine MARC records and assess metadata quality and its completeness.

- Select a random sample of titles from each identified package that cover various subjects, time periods, foreign titles, and cataloging records.

- Perform searches of sample titles across systems, including the local library catalog and the shared consortia catalog, the vendor platforms, and Google.

- Identify issues related to metadata, discovery, and searching.

- Create Analytics reports to gather data from Alma and Primo. Note: PSU Library’s migration to Alma/Primo was completed in late 2014, and therefore this analysis only includes data commencing in 2015; and is in keeping with the timeframe of expanded streaming media offerings from the library.

- Collect usage data from vendor platforms for comparisons.

- Analyze data and identify user discovery trends.

\section{Results and discussion}

\section{MARC records}

MARC record sets were created and exported from Alma. Each set of records for the identified collections was evaluated separately using MarcEdit, a software tool for editing MARC records and manipulating data (Reese, 2013). Comparisons were made using key criteria such as what cataloging standards were used for the description of the bibliographic records (AACR2 vs. RDA), where the records come from (OCLC or other providers), and whether the records contain a MARC 520 field (used for a summary, abstract, annotation, or overview describing the item's content), and/or 650 
field (used for subject headings). Entitlements lists were obtained from the vendors' administration sites; and the number of vendor supplied titles versus the number of cataloging records exported from Alma were counted and recorded. Details are shown in Figure 1 (collected as of Oct. 2019).

Figure 1: Comparisons of Title Lists, MARC Standards and Fields

\begin{tabular}{|c|c|c|c|c|c|c|c|c|c|c|}
\hline & \multicolumn{10}{|c|}{ Comparisons of Title Lists, MARC Standards and Fields } \\
\hline & $\begin{array}{l}\text { Academic } \\
\text { Video } \\
\text { Online }\end{array}$ & $\begin{array}{c}\text { BBC } \\
\text { Shakespea } \\
\text { re Plays }\end{array}$ & $\begin{array}{l}\text { British } \\
\text { Pathe }\end{array}$ & $\begin{array}{l}\text { C-Span } \\
\text { Video } \\
\text { Library }\end{array}$ & Docuseek2 & $\begin{array}{l}\text { Films on } \\
\text { Demand }\end{array}$ & Kanopy & Medici.tv & $\begin{array}{l}\text { Psychothe } \\
\text { rapy.net }\end{array}$ & $\begin{array}{c}\text { World } \\
\text { Newsreels } \\
\text { Online }\end{array}$ \\
\hline = SUBJECT & 46194 & 38 & 0 & 0 & 1564 & 30713 & 1496 & 1548 & 306 & 420 \\
\hline - 520 SUMMARY & 46308 & 38 & 0 & 0 & 1573 & 33062 & 1517 & 1563 & 306 & 37 \\
\hline$=$ AACR Standards & 23827 & 37 & 0 & 0 & 285 & 18411 & 485 & 5 & 6 & 415 \\
\hline in RA Standards & 23823 & 0 & 0 & 0 & 1292 & 14651 & 1233 & 1560 & 300 & 5 \\
\hline = Alma List & 47650 & 37 & 0 & 0 & 1577 & 33062 & 1518 & 1565 & 306 & 420 \\
\hline = Vendor List & 69338 & 37 & 0 & 0 & 1534 & 34115 & 486 & 2537 & 403 & 5864 \\
\hline
\end{tabular}

All of the extracted MARC records were examined carefully. All contained MARC 336 (Content type), 337 (Media type), and 338 (Carrier type), but that does not mean these records conform to RDA cataloging rules. Many of them are AACR2 records. This can be ascertained by evaluating the identifier/code in Leader/18 and MARC 040 field in bibliographic records. If a record is cataloged according to RDA, both Leader/18 (i) and 040\$e (rda) must be coded appropriately. MARC 336/337/338 fields can be added to AACR2 records to enhance access. Such records have been referred to as “enhanced” or "hybrid” records.

The authors noted that $72 \%$ of Docuseek2 records are RDA compliant. However, almost all of the World Newsreels records are non-RDA, although they are part of Alexander Street Press (ASP) offerings. The other ASP package, Academic Video Online (AVON), along with Films on Demand (FOD) are the library's largest streaming collections containing over 80,000 videos, and the cataloging records are 50/50 split between RDA and AACR2. Most records have OCLC system numbers in 
the 035 field, indicating a growing number of streaming video records available via OCLC and their partnerships with vendors.

Summary statements/contents notes are especially important for streaming media resources, as they provide descriptive information about the content and their intended use. 520 field/tag of the MARC 21 bibliographic record is used for such note; it is also recommended as a best cataloging practice to provide a summary for streaming media whenever such information can be readily found ((Best Practices For Cataloging Streaming Media Using RDA And MARC21, Version 1.1, April, 2018). The summary/abstract field is also keyword searchable, so it can facilitate more effective searches. It is noted that most of the records studied contain MARC field 520, adding value to these streaming video records.

Additionally, it is noteworthy that almost all of the records evaluated provide subject headings except for the World Newsreels Online (less than 1\% of the records have subject terms). Bibliographic records without subject headings could hinder access to content. Best practices recommend that all media resources be cataloged in accordance with current national standards and practices, including full subject access to ensure adequate access to media collections (ACRL, 2018).

As shown in Figure 1, no data were recorded for British Pathe and C-Span Video Library. They are openly available web resources, and there are no MARC records available at the item/portfolio level. It seems there is still a gap between subscription and free web content through the library catalog discovery. Further, these two collections are not included in the Ex Libris’ Primo Central Index for discovery yet as of this writing. However, users can search and find individual titles through the providers' platforms. British Pathe videos are also hosted on YouTube and can be discovered via Google search engine. 
As noted in Figure 1, most MARC records have been cataloged in the library database since the number of cataloged titles in Alma matches those provided by the vendors with a few exceptions. AVON seems to have a noticeable discrepancy, followed by World Newsreels Online, and Medici.tv. These services list many more entitlements on the Library's account than are cataloged in Alma. After some investigation, the authors determined that this is likely due to a delay between daily updates on vendors’ platforms and local internal cataloguing practices.

Fortunately, more and more content providers/vendors are partnering with OCLC to supply standard MARC records as part of their products offering now. This enables the library to provide timely access and allows batch process record loads for cost-effectiveness. Additionally, libraries rely on providers/OCLC to supply MARC record updates when existing titles dropped off and new titles added given the constant changing nature of streaming content similar to other electronic resources. Alma makes it easy to create sets of bibliographic records, compare lists, batch load vendor records, and perform global updates.

\section{Data analytics}

When dealing with video analytics, various sources were used, including content providers and Alma/Primo analytics reports. Ex Libris continues to improve and develop Sushi/COUNTER standards for media metrics. Currently, Alma/Primo Analytics cannot deliver complete data to reflect media metrics being used via vendor platforms. Although Ex Libris implemented COUNTER 5 in Alma Analytics recently, it is still in its infancy stage. Despite the limitations, the authors were able to create analysis using the Alma Analytics Link Resolver Usage feature based on material type to get a general sense of how video content has been used over time. Figure 2 shows usage data on the number of requests and the number of electronic services from 2015 
to 2019 (note: 2019 data are incomplete, as they were collected in early November 2019).

Figure 2: Alma Analytics Link Resolver Usage on Number of Requests/Electronic Services

Link Resolver Usage, Streaming Videos
\begin{tabular}{|l|r|r|}
\hline Request Year & Number of Requests & Number of Electronic Services \\
\hline 2015 & 12,849 & 13,950 \\
\hline 2016 & 23,199 & 26,673 \\
\hline 2017 & 28,069 & 32,596 \\
\hline 2018 & 38,618 & 45,258 \\
\hline 2019 & 44,306 & 52,235 \\
\hline
\end{tabular}

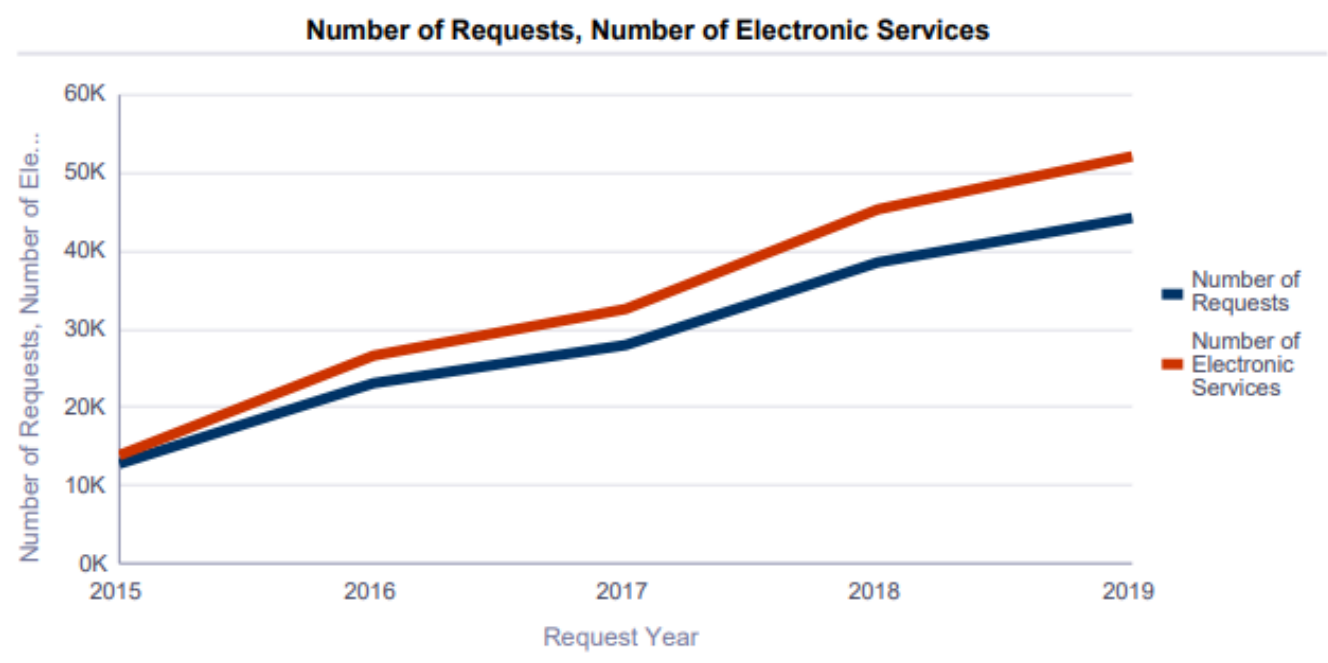

Per ExLibris' definitions, “Number of Requests” means the number of times an OpenURL request was sent to the Alma Link resolver when Primo searching was executed. "Number of Electronic Services" means the number of electronic services that appear when a user selects View it. Figure 2 demonstrates the rising trend in accessing streaming content through the library catalog over the last five years with 13,950 clicks to view content in 2015 to 51,727 clicks in 2019.

Evidently, more and more users are starting to look for streaming videos via the library catalog (Primo discovery interface), which is contrary to previous assumption. The data also reveals information on the origin of user searches when "Source Type" is added in the analysis. Based on this analysis, it is revealed that most users (64\%) were 
directed to streaming content via the link selected from Primo or Primo Central Index, $10 \%$ were from within Alma staff user interface, and the rest (26\%) was from when the link is selected from another source, such as Web of Science, Ebsco, Pubmed, Google Scholar, and all other external sources.

Similarly, this growing trend is also demonstrated in Primo Analytics as shown in Figure 3. Interestingly, this report also shows that more streaming content was viewed via off-campus than on campus. It is also worth noting that the number of filtered searches is going up, as indicated in Figure 3.

Figure 3: Primo Analytics on Total Sessions Viewed (note: data gathered in early November 2019.)

Total Sessions, Using Streaming Video Filter

\begin{tabular}{|l|r|r|r|r|}
\hline Year (date) & Total sessions & Using streaming video filter & Signed In & On Campus \\
\hline 2014 & 286,664 & & & \\
\hline 2015 & 940,697 & 14 & $1,087,777$ & 11,165 \\
\hline 2016 & $1,552,032$ & 270 & $1,442,436$ & $1,545,996$ \\
\hline 2017 & $1,764,475$ & 425 & $1,659,325$ & $1,147,959$ \\
\hline 2018 & $1,749,886$ & 2,808 & $1,725,521$ & 664,379 \\
\hline 2019 & $1,622,120$ & 2,380 & $1,488,846$ & 603,654 \\
\hline
\end{tabular}

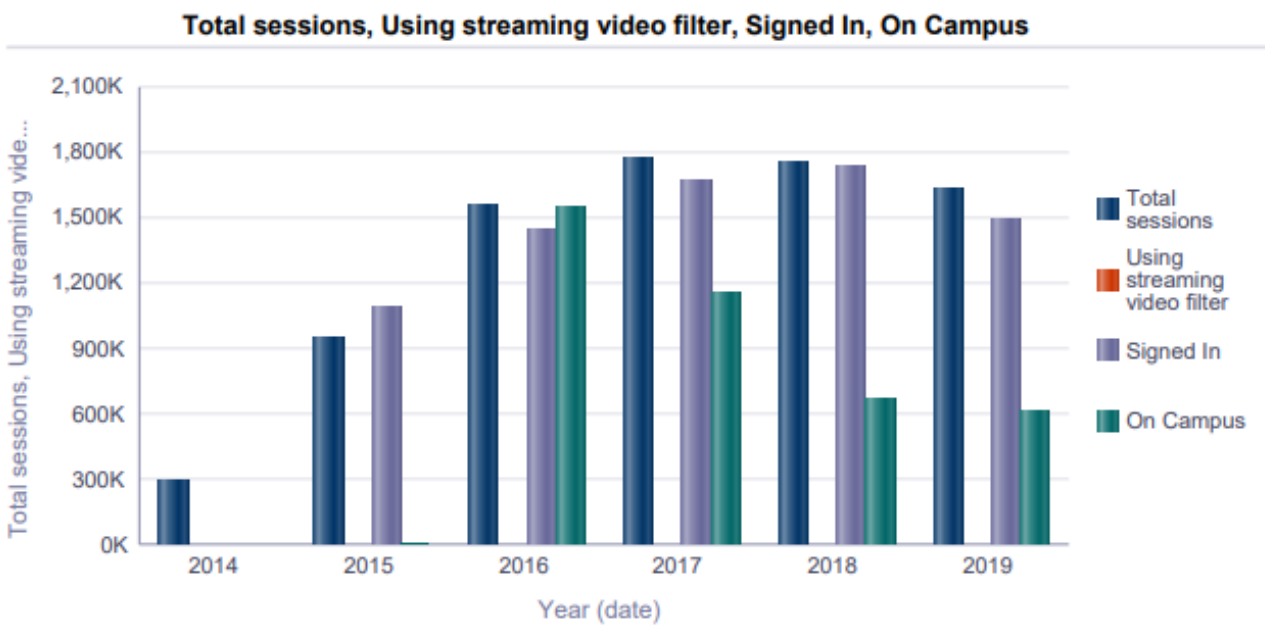

Vendor-supplied usage statistics further indicate this rising trend.

Figure 4 shows video usage statistics collected from selected vendors’ administration platforms over the past three years (2016, 2017, 2018). Note: COUNTER 4 statistics are used when available, however some of these are not COUNTER compliant. Some 
analytics data indicate searches, page views, and video views. The authors attempted to present video view data below.

Figure 4: Vendor Usage of Selected Streaming Platforms 2016-2018

\begin{tabular}{l|l|l|l} 
COLLECTION & $\mathbf{2 0 1 6}$ & $\mathbf{2 0 1 7}$ & $\mathbf{2 0 1 8}$ \\
\hline Academic Video Online & n/a & 4519 & 8687 \\
\hline Docuseek 2 & 858 & 1342 & 1169 \\
\hline Films on Demand & 5468 & 4885 & 3631 \\
\hline Kanopy & 12452 & 24989 & 32321 \\
\hline Medici.tv & 277 & 616 & 3079 \\
\hline Psychotherapy.net & 18 & 293 & 1760 \\
\hline World Newsreel Online & 19 & 25 & 45 \\
\hline
\end{tabular}

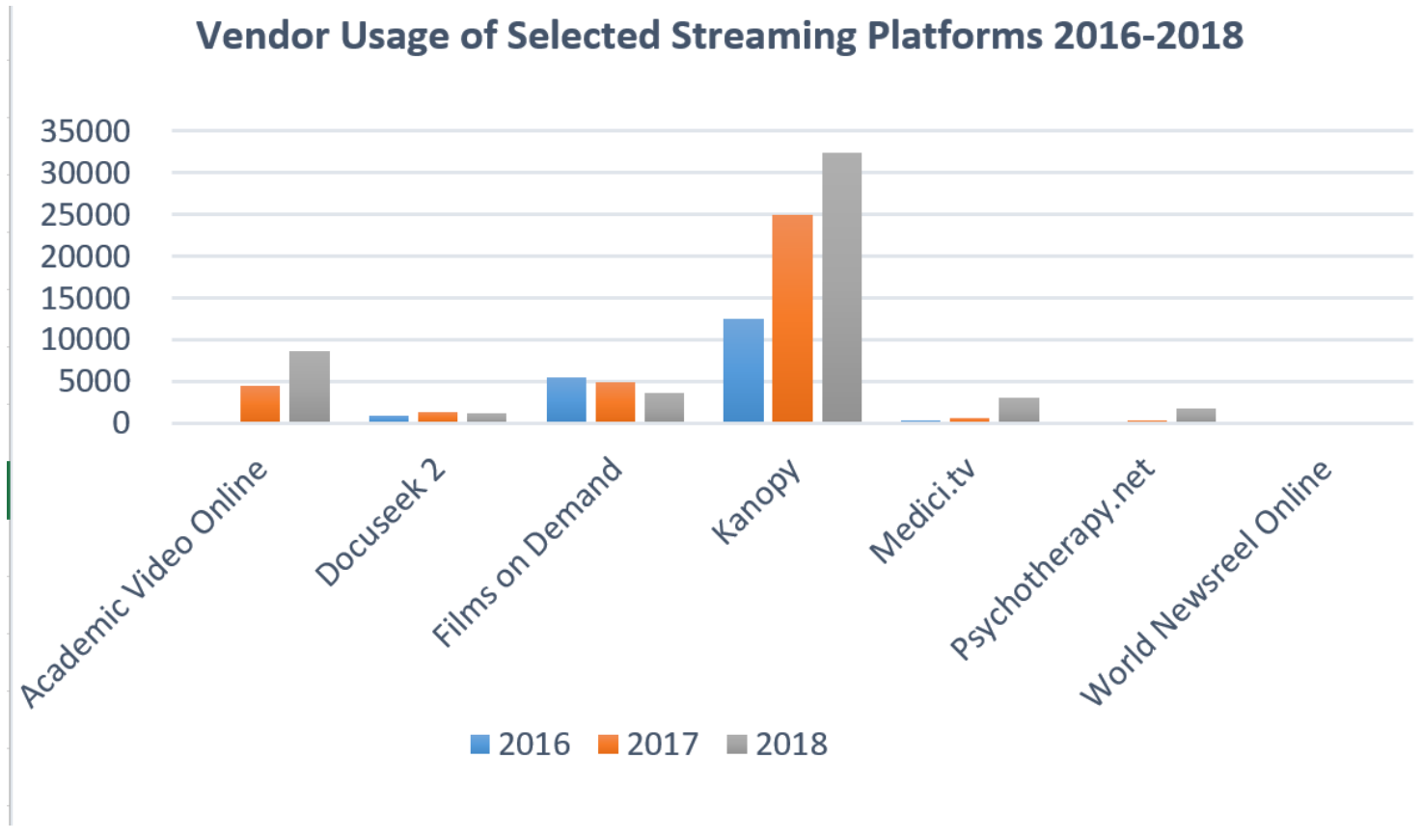

Vendor-supplied data indicate slightly different video metrics for measuring the success of video content use. Most vendors provide usage data on view count, play rate, and click-through rate. ASP also includes measure on engagement and impact while Kanopy or FOD use a few different video metrics, as stated above, such as FOD's “record views”, “regular searches”, “result clicks”, and "searches-federated and automated". This exemplifies the many different data points available to libraries when 
examining their analytics. However, when comparing streaming services, a standardized approach, such as COUNTER compliant data, is useful. Otherwise, the comparisons are not completely informative.

Librarians are aware that measurement of video use is more complex than that of materials in other formats due to the visual and interactive nature of this resource. David Parker (2107), Senior Director, Video and Health Sciences for Alexander Street Press, shed some light on video metrics from an industry point of view, and argues that the use of videos cannot be measured only by cost per use (key measure); user engagement and impact is equally an important measure not to be overlooked. "ROI, for a producer of video content, may be measured by number of views and dollars earned, but it may also be measured by length of views (engagement), number of classes where the video is central to the syllabus (impact of view) or longevity of views (number of years the video remains active within the academic community)” (p. 72). Parker advocates to measure how the video impacts teaching process and effectiveness of learning process in a more meaningful way, which could be better evaluated in a classroom setting.

Engagement and impact is certainly an important part of the user video experience and these metrics would help librarians get a more comprehensive view of video content used to measure return on investment. It is hoped that streaming content providers and vendors would offer standardized video metrics for library use.

\section{Metadata and content display}

As evidenced by the data analysis, the integration of video metadata in the library catalog has increased the visibility of streaming videos in the library catalog, which is part of a larger trend in today’s academic library environment.

However, discoverability can still be hindered if issues on metadata quality and content display are not addressed. This study, therefore, explored more areas to 
determine possible factors affecting streaming content discovery and exploration. To that end, the authors performed some testing on a random sample of titles selected from several vendors, from various time periods, foreign titles, and cataloging records to ensure breadth. Searches of sample titles were performed across systems (the library catalog, vendor platforms, and Google) over the course of a few months.

\section{Discussion of sample search results}

The authors performed sample searches to see how streaming resources are discovered through the library catalog (Primo) and vendor platforms. Examples are provided below to illustrate various issues.

\section{Example 1: Issues related to non-Romanized scripts}

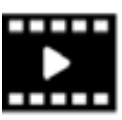

\section{EVIDEO}

My song is = Na ŭi norae nŭn

directed by Ahn Seul-ki.

Seoul : Indiestory

2007

Online Access >

This video is found and retrieved on the first search results page via both English and transliterated titles. However, if searched using Korean script since the film is in Korean, Primo cannot find the title; not because of its capability, but due to lack of non-Romanized data in the record (lacking the MARC 880 Field for Alternate Graphic Representation) in this case. Enriched metadata would enhance discovery if foreign titles are searched. The discovery system is moving toward being able to better support non-Latin scripts, so it is recommended that vendor records keep pace with those trends.

\section{Example 2: Issues related to cataloging updates}


EVIDEO

Freedom : a history of us.

Episode 15, Marching to freedom

land

produced \& directed by Philip B. Kunhardt III, Nancy Steiner, Peter

W. Kunhardt.

Arlington, VA: Public Broadcasting Service PBS

2003

O Online Access >

EVIDEO

Freedom : a history of us.

Episode 7, What is freedom?

produced \& directed by Philip B. Kunhardt III, Nancy Steiner, Peter

W. Kunhardt.

Arlington, VA: Public Broadcasting Service PBS

This example indicates incomplete holdings of episodes in this series from the PSU Library’s catalog. But when searching on the vendor platform, many more episodes are discoverable. Also, the linking is problematic, directing the user to the general landing page of the platform, and not to the film itself. While workflow improvements have been made, the challenge of keeping pace with vendor updates remains. Therefore, sometimes searches on the vendor platforms are more up to date. The lag in catalog updates understandably does lead to a discrepancy between the library's entitlements and what is discoverable in the catalog. This could be an inherent problem and challenging for libraries in general.

\section{Example 3: Issues related to interface}

EVIDEO

Child therapy case consultation

Violet Oaklander, $\mathrm{PhD}$.

Mill Valley, California : Psychotherapy.net

2011

Online Access > 


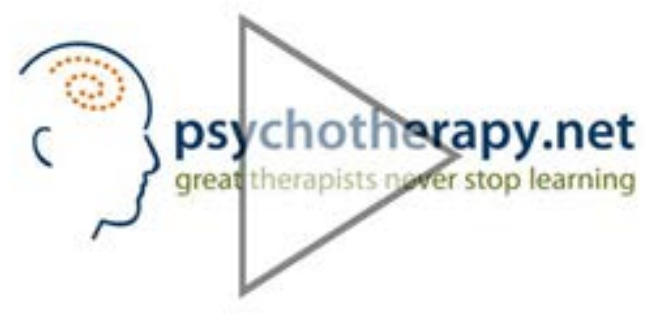

When searching videos for Psychotherapy.net, discoverability in the catalog was efficient, however, when clicking on the link from the catalog record, the user is taken to the vendor platform, but the movie won't load; or so it appears, there is a small play button which requires the user another click to see the film. This seems to be an unusual interface of the vendor platform; which was mistakenly thought of as a vendor error and the link was incorrect. The authors believe this could be a misleading signal affecting user experience. However, a month later, while re-checking this situation before article submission, the authors discovered that the interface has changed, and the video displays immediately. This was a favourable change in the vendor's interface, and no doubt in response to their patrons' feedback.

\section{Example 4: Issues with multiple versions of a film}


EVIDEO

Metropolis

Transit Film ; Friedrich Wilhelm Murnau Stiftung ; an UFA production ; distributed by Parufamet ; director, Fritz Lang ; [produced by Erich Pommer]; screenplay, Thea von Harbou.

New York, NY : Kino International

1927

(f) Online Access >

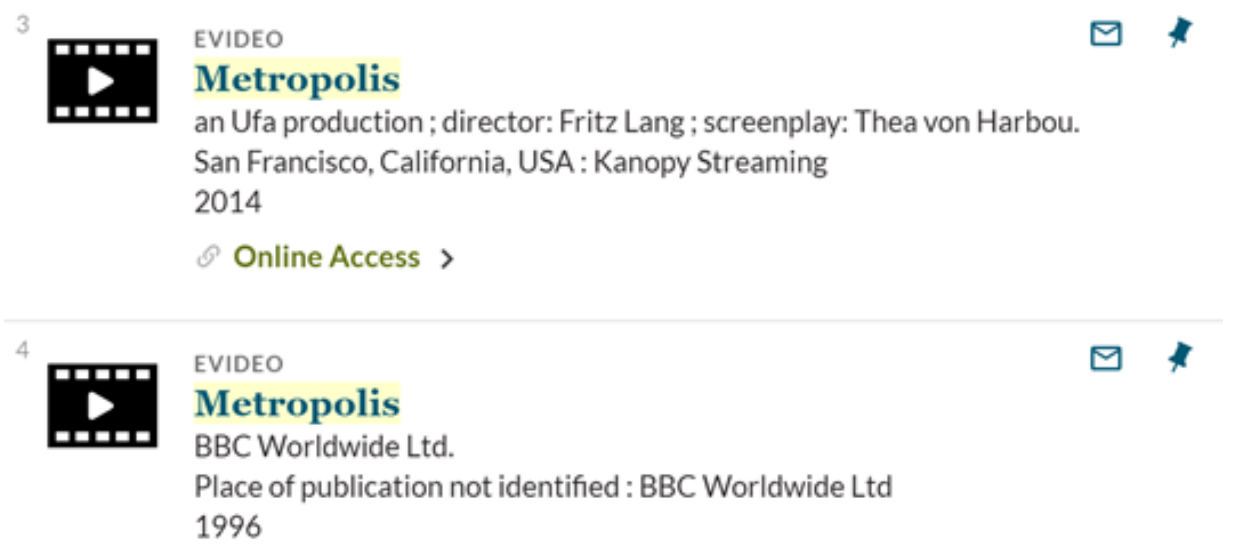

View It

Available online at: Silent Film Online []

Public notes:
Silent film with English intertitles and subtitles and musical background

Other Options

Place this item on Course Reserves [

Some video titles can be challenging when searched in Primo Discovery, such as a one-word title, or common term names, because the results can be numerous. This example shows a title search retrieving multiple records for the same video but from different providers with slightly varying content and styles. When faculty want to use a film for class, they are often only interested in one particular version of the content, and not the 4-5 versions discovered in the catalog. A local solution in this case is to add a special message in the Public Note of the record to help identify preferred version.

\section{Example 5: Issues with local records display}


EVIDEO

Le voyage dans la lune $=A$ trip to the

moon

[directed, produced, edited] de/by Georges Méliès. The extraordinary voyage

/ Steamboat Films presents; with the participation of France Télévisions ; a

co-production with Lobster Films ...

Los Angeles, Calif. : Flicker Alley

2012

Online Access >

Locally hosted video records, such as this example, are hosted on PSU's

MediaSpace platform. It was noted by the library’s Public Services department recently that this video does not show up on the first page of search results when students look for it in the library catalog. It turned out this issue can be resolved by adjusting some parameters in the institution’s Primo Back Office configurations to influence the ranking of the local records, so that this type of record can appear on the first page. As a result of this change, discovery of this streaming video is greatly improved. This example illustrates that it is important to communicate with systems vendors to make discovery tools work more effectively for all types of materials, especially for specialized materials such as streaming media resources. As Hoover states (2016): "Discovery tools are customizable, and sometimes small changes can be made that drastically affect the way a particular type of resource is retrieved or displayed" (p. 41).

\section{Example 6: Issues with variant titles}

EVIDEO

Sunset Blvd.

a Paramount Picture; written by Charles Brackett, Billy Wilder and D.M. Marshman, Jr.; produced by Charles Brackett ; directed by Billy Wilder. Hollywood, California : Paramount Pictures 1950

Online Access >

This example demonstrates that variant titles can affect the way streaming content is discovered and retrieved. When searching for "Sunset Boulevard" in Primo, 
the film shows up on the third page of search results, the $28^{\text {th }}$ hit, instead of the first page, because the 245 Title field is "Sunset Blvd.”. This makes it difficult to be found. Studies have shown that students have a tendency to rely only on the first page of search results, and usability testing has revealed 92 percent of the resources used by students were found on the first page of search results (Asher, Duke, \& Wilson, 2013).

After adding "Sunset Boulevard” as an alternative form of the title in the 246, the film is now easily discoverable, appearing on the first page of search results. As noted, standardized metadata is the key to ensure user success in discovery.

\section{Conclusion}

This study reveals several issues and possible trends in academic libraries’ offering of streaming media content, with the focus on catalog discovery. It underscores the increased importance of streaming video cataloging and metadata ingestion in the library catalog and discovery service. The need for quality and enriched metadata, 'onestop shop’ discovery tools, and effective content display for streaming resources is gaining traction and increasingly demanded. Best practices provide libraries with tools, standards, and resources in handling this type of streaming content.

Data analysis also demonstrates an upward trend for content providers to incorporate video clips into their indexed content. For example, Gale’s Local Broadcast Video Content that can now be discovered through Communications and Mass Media Collection in Primo. Another emerging trend in this regard is the increased availability of video segments provided by content providers, which allows users to search for more granular, topic focused subsets of the video content, a similar concept to article-level and chapter-level discovery. Many ASP and Sage videos have started offering such segments. 
In May of 2019, NISO announced a new project to develop best practices for ensuring findability of video and audio outputs from scholars. The NISO website states:

The National Information Standards Organization (NISO) Voting Members have approved a new project, Assess Video and Audio Metadata and Standards for Academic Research and Professional Information, to determine best practices and recommendations for metadata associated with scholarly output and instructional materials in video and audio formats. NISO is now forming a working group; community members with an understanding of the various use cases of such media are invited to participate in this initiative intended to formulate recommendations for consistent and precise identification and description of these increasingly common presentations of research findings. (para. 1)

This is an exciting time for librarians, technologists, archivists, publishers, and discovery service providers to work together to make advanced media materials more discoverable, accessible and useful for all library users.

\section{Acknowledgement:}

The authors would like to acknowledge the librarians at Portland State University for their feedback about their experiences during this study.

\section{Disclosure statement:}

No potential conflict of interest was reported by the authors

\section{References}

Asher, A., Duke, L., \& Wilson, S. (2013). Paths of Discovery: Comparing the Search Effectiveness of EBSCO Discovery Service, Summon, Google Scholar, and 
Conventional Library Resources. College \& Research Libraries, 74, 464-488.

doi:10.5860/crl-374

Association of College and Research Libraries. (2018). Guidelines for Media Resources in Academic Libraries (2018 Revision). American Library Association, September 6, 2006. Retrieved from http://www.ala.org/acrl/standards/mediaresources. Document ID: 9bce3971-1eb1-1c54-2191-7c3566164198

Barford, J., \& Weston, C. (1997). The use of video as a teaching resource in a new university. British Journal of Educational Technology, 28(1), 40-50. doi:10.1111/14678535.00005

Beisler, A., Bucy, R., \& Medaille, A. (2019). Streaming video database features: What do faculty and students really want? Journal of Electronic Resources Librarianship, 31(1), 14-30. doi:10.1080/1941126X.2018.1562602

Best Practices For Cataloging Streaming Media Using RDA And MARC21, Version 1.1, April, 2018 https://www.olacinc.org/sites/default/files/Streaming_Media_RDAApril2018_a.pdf

Bossenga, S., Bulock, C., DeGreve, L., Doyle, C., Goetz, T., Lindemann, R., \& Uth, C. (2014). Streaming video in academic libraries: A white paper. CARLI Commercial Products Committee 2013-2014. Retrieved from https://www.carli.illinois.edu/sites/files/files/2014CommercialProductsCommStreaming VideoinAcademicLibraries.pdf. 
Breeding, M. (2015). The future of library resource discovery. Baltimore, MD: NISO. [Google Scholar] http://citeseerx.ist.psu.edu/viewdoc/download?doi=10.1.1.675.3000\&rep=rep1\&type=p df.

Dixon, J. (2017). The Academic Mainstream: Streaming Video, Library Journal. Retrieved from https://www.libraryjournal.com/?detailStory=academic-mainstreamstreaming-video.

Farrelly, D. (2014). Part II: Acquisitions, Chapter 18: Streaming Video. In Albitz, B., Avery, C., \& Zabel, D. (Eds.), Rethinking collection development and management (pp. 215-232). Santa Barbara, California, Libraries Unlimited.

Farrelly, D. (2015). Streaming Video Passes the Tipping Point! Now What? ALCTS Presentation. Retrieved November 14, 2019.

http://downloads.alcts.ala.org/ce/2015_1111_CSMseries_Part2_Streaming_Video_Slide s.pdf.

Farrelly, D. (2016). Digital video: Merrily merrily, merrily, merrily, wading into the stream: Freed from the limitations of a physical artifact, streaming videos are available anywhere, anytime ... no need to reserve in advance, arrange for equipment, or pick up and return. Computers in Libraries, 36(9), 4-5. Retrieved from http://www. infotoday.com/cilmag/nov16/farrelly-Digital-Video-Merrily-Merrily,-Merrily-MerrilyWading-Into-the-Stream.shtml. 
Farrelly, D., \& Hutchison, J. (2014). ATG Special Report: Academic Library Streaming

Video: Key Findings from the National Survey. Against the Grain, 26(5), 73-75. doi:10.7771/2380-176X.6852

Hanrath, S., \& Kottman, S. (2015). Use and usability of a discovery tool in an academic library. Journal of Web Librarianship, 9(1), 1-21. doi:10.1080/19322909.2014.983259

Hoover, J. (2016). Remaining discoverable: Video collections in EDS. Journal of Electronic Resources Librarianship, 28(1), 36-41.

doi:10.1080/1941126X.2016.1130457

Hutchison Surdi, J., \& Farrelly, D. (2016). Academic Library Streaming Video Revisited. ALA Annual Conference, Orlando, Florida, June 26, 2016.

Leffler, J., Hayden, J., \& Enoch, T. (2017). Juggling a New Format with Existing Tools: Incorporating Streaming Video into Technical Services Workflows. The Serials Librarian, 72(1-4), 102-104. doi:10.1080/0361526X.2017.1284498

Leonard, E. (2015). Great Expectations: Students and Video in Higher Education. Retrieved from https://studysites.sagepub.com/repository/binaries/pdfs/StudentsandVideo.pdf. 
Library of Congress. (2008). On the Record: Report of the Library of Congress Working Group on the Future of Bibliographic Control. Retrieved from http://www.loc.gov/bibliographic-future/news/lcwg-ontherecord-jan08-final.pdf.

Lohmann, S., \& Frederiksen, L. (2018). Faculty Awareness and Perception of Streaming Video for Teaching. Collection Management, 43(2), 101-119.

Meadows, A. (2019). Better Metadata Could Help Save The World! Retrieved from https://scholarlykitchen.sspnet.org/2019/06/11/better-metadata-could-help-save-theworld/.

Otto, J. (2014). University Faculty Describe Their Use of Moving Images in Teaching and Learning and Their Perceptions of the Library’s Role in That Use. College \& Research Libraries, 75(2), 115-144. doi:10.5860/crl12-399

Palvia, S., Aeron, P., Gupta, P., Mahapatra, D., Parida, R., Rosner, R., \& Sindhi, S. (2018). Online Education: Worldwide Status, Challenges, Trends, and Implications. Journal of Global Information Technology Management, 21(4), 233-241. doi:10.1080/1097198X.2018.1542262

Parker, D. (2015). Blurring Lines: Libraries and Video: Measuring ROI Really, How?. Against the Grain, 27(1). doi:10.7771/2380-176X.7022

Reese, T. (2013). “About MarcEdit”. MarcEdit Development. Retrieved from https://marcedit.reeset.net/aboutmarcedit. 
Romaine, S., \& Wang, J. (2017). When ERM Met Alma: The Intricacies of Content Management in a Shared Consortia Landscape. Serials Review, 43(1), 17-27. doi:10.1080/00987913.2017.1279896

Shapiro, S. (2018). Academic Librarians, Information Overload, and the Tao of Discovery. The Journal of Academic Librarianship, 44(5), 671-673. doi:10.1016/j.acalib.2018.07.004

Shephard, K. (2003). Questioning, promoting and evaluating the use of streaming video to support student learning. British Journal of Educational Technology, 34(3), 295-308. doi:10.1111/1467-8535.00328

Strauch, K., \& Gilson, T. (2016). Multi-Perspective Interview of Video Streaming featuring: Leandra Preston-Sidler, University of Central Florida; Kiren Shoman, SAGE Publishing; and Michael Arthur, The University of Alabama. Against the Grain, 28(6) doi:10.7771/2380-176X.7569

Wong, W. (2014). Boosting Bandwidth: Colleges Are Upgrading Their Network Infrastructure to Support Next-Generation Technologies. Community College Journal, 85(1), 24-28. Retrieved from http://search.ebscohost.com/login.aspx?direct=true \&db=ehh\&AN=97763933\&site=eho st-live. 


\section{APPENDIX}

Selected survey questions for library faculty about streaming video content in the library

Where do you usually start when searching for a streaming video (for a library user or for yourself?)

How do your faculty and students locate and access streaming video? (as best as you can tell?)

What do you see as the greatest challenges involved in the library offering streaming video content?

What are the greatest benefits to offering streaming content?

In your experience, is it easy to search for streaming content in the library catalog? If you would like, please explain.

If you have additional comments about vendor platforms/databases and their role in providing search technology for libraries, please share.

NOTE:

This is an Accepted Manuscript of an article published by Taylor \& Francis Group in Journal of Electronic Resources Librarianship on 01/06/2020, available online: https://doi.org/10.1080/1941126X.2020.1739818. 